\title{
Social workers' experiences with whistleblowing: To speak or not to speak?
}

\author{
Sally Raymond ${ }^{1}$, Liz Beddoe ${ }^{2}$ and Barbara Staniforth ${ }^{2}$
}

\begin{abstract}
INTRODUCTION: Reporting perceived inadequate and/or harmful practice has become known internationally as whistleblowing. Social workers have a responsibility to uphold ethical standards and may blow the whistle when faced with what they perceive as unethical conduct.

METHOD: A small-scale, qualitative study explored the experiences of 10 social workers in Aotearoa New Zealand who, having observed what they believed to be poor or unsafe practice, attempted to have their concerns addressed by reporting to a third party or blowing the whistle.

FINDINGS: The research reveals common experiences of limited support for, and retaliation from colleagues and organisations towards, those who spoke out. Participants experienced both personal and professional consequences.

CONCLUSIONS: The research identifies the need for appropriate processes and support for whistleblowing social workers and their employing agencies. Social workers need to be better informed about their rights and responsibilities under the Protected Disclosures Act (2000).

KEYWORDS: whistleblowing, accountability, social work ethics, professional misconduct
\end{abstract}

Whistleblowing in social work has not received a great deal of attention in practice or research and in a search undertaken, no Aotearoa New Zealand research was located. This article reports on a small, exploratory qualitative study of whistleblowing that is a starting point in encouraging dialogue on this important professional concern.

While there are many definitions of whistleblowing, Mansbach and Bachner's (2009) definition is helpful: "whistle blowing is the disclosure by a person working within an organization of acts, omissions, practices, or policies by persons within the organization that wrong or harm a third party" (p. 18). De Maria (1996) states that "the short answer is that whistleblowing is a form of dissent" (p. 15), while Lennane suggests "an alternative, shorter definition is principled organisational dissent"
(1993, p. 249). Another helpful definition is offered by McDonald and Ahern (2002) who identify a whistleblower as someone "... who identifies an incompetent, unethical or illegal situation in the workplace and reports it to someone who has the power to stop the wrong" (p. 305).

Preston-Shoot asserts that "the number of social work whistle blowers remains low" (2010, p. 184). This raises the question: Why do social workers not speak out? Is it because they feel a sense of loyalty to their colleagues or to their organisations? If so, does this loyalty take precedence over adhering to ethical codes? Are they frightened of possible retaliation? Or is it simply that they do not know where to turn? De Maria (1996) notes of social workers who perceive poor practice and face the dilemma of whether or not to act:
${ }^{1}$ Northland District Health Board, New Zealand

2 University of Auckland, New Zealand
AOTEAROA

NEW ZEALAND SOCIAL WORK 29(3), 17-29.

CORRESPONDENCE TO: Liz Beddoe e.beddoe@auckland.ac.nz 
They often struggle not with but against the dilemma by acting on values they believe are higher and more important than agency loyalty and career development. (De Maria 1996, p. 22)

The aims of this study, undertaken as part of a Master of Social Work degree, were to explore: 1) the experiences of social workers who were aware of perceived unethical behaviours or potentially harmful practice; 2) what they chose to do with that knowledge; and 3) determine the consequences of those decisions. The researcher, and her two supervisors hoped to find an answer to the question "to speak or not to speak?" with the hope that this may be able to assist social workers in future who face a similar dilemma about what to do. The focus of this article is on experiences of 10 social workers in Aotearoa New Zealand who blew the whistle on perceived poor practice. The focus was on the process of whistleblowing. As such, we do not interrogate in any depth the nature of their reported concerns, but start and finish our exploration with the reported dilemma they faced when encountering what they deemed unsafe or unethical practices.

We acknowledge that terms such as unethical practice are loaded with potential ambiguity, due to the highly contextual nature of professional values and ideas about conduct that "are not based on universally valid, abstract principles" (Banks, 2008, p. 1243). When these terms are used in this article they reflect the narratives shared with the interviewer.

\section{Literature}

An initial search found literature about whistleblowing but very little specific to social work, thus the search was expanded. The extensive work of Glazer and Glazer (1989) from the USA, was a starting point to explore the phenomenon of whistleblowing. Glazer and Glazer interviewed 64 whistleblowers and recount the experience of a mental health social worker who drew attention to unethical practice.
The cost for this social worker was high, with serious stress-related health outcomes and repercussions in relationships with employers and others. The social worker received limited support and Glazer and Glazer (1989, pp. 253-254) urge professional associations to "provide their members with direct help that goes beyond platitudes ... associations cannot turn their backs if they are to keep their legitimacy as primary spokespersons for professional rights and responsibilities".

Whistleblowing in social work should perhaps be viewed as a special form of advocacy, as it is often about exposing unethical or other harmful behaviour on behalf of service users. Indeed advocacy is a term more commonly used than whistleblowing in the social work profession (Greene \& Latting, 2004; Jackson et al., 2010; Kline \& Preston-Shoot, 2012). Furthermore, Green and Latting (2004) also advise practitioners who are considering whistleblowing to access expert advice and external emotional support as it is likely that their own judgement and stability will be called into question. The literature review suggests that most whistleblowers did not seek support prior to reporting concerns, which then left them vulnerable to the retaliation they encountered.

For social workers, especially those new to the profession, discovering colleagues they deem to be practising unsafely presents an ethical dilemma in itself and the knowledge of how and where to go to have this addressed is yet another challenge. Reporting their concerns may, at the time, be their main focus and the idea they need support may come later, given the evidence in the literature that retaliation is a consistent consequence of speaking out (De Maria, 1996; Hedin \& Mansson, 2011; Hunt, 1998; Jackson et al., 2010; Lennane, 1993; Mansbach \& Kaufman, 2009; McAuliffe \& Sudbery, 2005; Moore \& McAuliffe, 2010).

Mansbach and Bachner (2009) explored the likelihood of social work students blowing 
the whistle in different situations. The students were asked to rate three ethical dilemmas on the degree of their seriousness and, if faced with the dilemma, report the likelihood they would blow the whistle. The findings revealed that they would have been most likely to report within their organisation and the likelihood of reporting was greater when harm and injustice were caused to the most vulnerable clients. Noting the paucity of social work literature about whistleblowing, Mansbach and Bachner (2009) argue that it should be introduced in the curriculum of social work education, as an aspect of ethics and advocacy as proposed by Greene and Latting (2004) because: "[i]n doing nothing to stop harmful conduct by colleagues or supervisors, social workers may violate their basic professional commitment to promote and protect the welfare of their clients" (Mansbach \& Bachner, 2009, p. 19). It is not known the extent to which this recommendation has been taken up.

The Aotearoa New Zealand Association of Social Work (ANZASW) Code of Ethics (2008) Section 5.7 states:

Both the everyday and professional conduct and integrity of members must be beyond reproach. Where a situation is too serious to be resolved in discussion with the colleague concerned, instances of professional misconduct or unethical behaviour by that colleague (particularly where this involves actions that are harmful to clients) must be brought to the attention of the appropriate bodies. (p. 13)

However, the appropriate bodies are not identified. Despite the references to the codes of conduct and codes of ethics of the professional associations in much of the literature, Doel et al. (2010) reported that, when faced with boundary issues, the participants favoured agency codes of conduct over professional codes of practice but were even more likely not to draw on either, rather their response relied on "an implicit personal code" (p. 1875). However, in an analysis of agencies' policy documents, Doel et al. (2010) noted all policies were concerned with how possible boundary violations would affect the employers' reputation, whereas the main concerns of the professional bodies were centred on fitness to practice and public confidence in the profession. How boundaries were perceived may reflect two contrasting points of reference. One side was concerned with "... how does this affect the service user?" while the other side's concern was "... how does this affect the agency?" (p. 1881). Doel et al. (2010) suggest that an important question for consideration is: "the most likely people to be aware of boundary issues are colleagues but what likelihood is there of whistleblowing?" (p. 1883). They conclude by suggesting the best approach for the profession was to provide regular opportunities for engagement with ethical issues in order to inform practice and to "remain ethically alert" (p. 1884).

\section{Organisational responses}

Organisational defensiveness is described in the literature as a significant concern, as agency responses are crucial in determining a satisfactory outcome of whistleblower actions. A continuing theme in the literature is that when there are concerns, employees, like the students referred to above, are more likely to report poor practice internally and consider going externally only if not satisfied with the organisation's response (Greene \& Latting, 2004; Hedin \& Måansson, 2011; Hunt, 1998; Lennane, 2012; Mansbach et al., 2009). Hunt (1998) asserts that, although social workers who place clients at risk must be held accountable, so must the organisation that hired them and in some cases, kept them in their positions despite concerns being raised.

\section{The consequences of whistleblowing: retribution}

The literature consistently reports negative impacts of whistleblowing on those who 
report harmful practice. The impacts reported included low-level emotional issues, right through to longer-term, significant psychological and physical impacts, along with personal impacts within the workplace and on whistleblowers' careers. Retribution is one of the consequences of whistleblowing which can be most distressing to the practitioner concerned (De Maria, 1996; Lennane, 2012).

Retribution can come in different forms, official and unofficial, as noted by De Maria (1996) in a report on the findings of the Queensland Whistleblower Study (QWS) (De Maria \& Jan, 1994). This study reported on the experiences of 102 public sector workers, which included social workers and other welfare professionals (De Maria, 1996), of whom 96\% stated they were socially ostracised or abused at work as a result of blowing the whistle. De Maria (1996) provides two case studies, from the QWS (De Maria, et al., 1994), where social workers had witnessed and reported what was considered to be unsafe practice, and where negative consequences transpired for the whistleblowers. As a consequence of the processes that transpired after reporting their concerns, one social worker reported repeated bouts of depression and at times felt suicidal, while another had no support and received threatening phone calls. One participant was followed at night while in her car and also had the brake hoses on her car cut. De Maria (1996) states, "[o] ur research also suggests that workers in welfare agencies cannot expect reprisal immunity simply because their agency proclaims a spiritual worldview or a secular caring mission or that they work within a social justice framework" (p. 20).

\section{The consequences of whistleblowing: long-term effects}

De Maria (1996), Jackson et al. (2010) and Lennane (2012) all identify the retaliation suffered by those who have reported poor or dangerous practice and note that these impacts can also be long term. Long-term effects were also noted by Lennane (2012) in a detailed survey of 35 Australian whistleblowers from a range of occupations. As this study was reasonably small, the results were compared to a similar survey of 233 US whistleblowers (McMillan, 1990, cited in Lennane, 2012). In both studies, significant numbers of those affected had lost their jobs or were demoted, experienced difficulties with alcohol, and $6 \%$ of Australians and $10 \%$ of American participants reported an attempted suicide. Anxiety, stress and anger were long-term effects reported. Lennane noted, "[i]t was clear from the survey that the damage done to the whistleblower, and particularly to the family, increases as time goes on" (2012, p. 257). Lennane recommends that those thinking about blowing the whistle, internally or externally, should line up their support before they start and suggests, " $[\mathrm{t}]$ he most reliable support will come from outside the organisationsupport from within is likely to crumble once a typical employer reaction starts" (2012, p. 256).

\section{Support needs}

Social workers are expected to engage in regular professional supervision and support is often identified as a natural part of the supervision process. It is recognised that social workers often work with the most vulnerable members of society, at times deal with challenging situations and risk developing burnout. Supervision is at the core of practice for providing the opportunity for social workers to reflect on their practice, address their concerns, receive the support they need to avoid burnout and encourage safe practice (Beddoe, Davys, \& Adamson, 2014).

In an Australian study, which explored who social workers talked to when faced with an ethical dilemma, McAuliffe and Sudbery (2005) state that conflicts between responsibilities to individual clients and responsibilities to colleagues were commonplace. In one such situation, reported by McAuliffe and Sudbery, a 
worker in a mental health service advocated on behalf of a client who she believed was being discriminated against and supported the client in making a complaint. This action "effectively destroyed collegial relationships and damaged interprofessional collaboration" (2005, p. 25).

McAuliffe and Sudbery found that supervision, colleagues, and family and friends were the main sources of support. When discussing ethical issues involving colleagues, they note that it was quite difficult for social workers "to openly discuss concerns with others in or outside the workplace" (2005, p. 34). These consistent experiences of negative outcomes of reporting concerns reported in the literature have led to actions on both sides of the Tasman.

The Protected Disclosures Act, which came into force on 1 January 2000, was designed to protect whistleblowers from official reprisals. It provides a source of information and guidance to Aotearoa New Zealand practitioners. Whistleblowers Australia, established in 1991, supports whistleblowers, both before and after exposing incidents of unsafe practice or corruption in the workplace. Their aim "is to help promote a society in which it is possible to speak out without reprisal about corruption, dangers to the public and environment, and other vital social issues, and to help those who speak out" (Whistleblowers Australia). However, as noted by Whistleblowers Australia (and as identified in most of the literature), this type of legislation does not provide whistleblowers any protection from retaliation and abuse coming from others in the workplace.

The review of the literature thus provided a wealth of information about reported consequences of whistleblowing in other jurisdictions but no information about the experiences of social workers in Aotearoa New Zealand who chose to blow the whistle. This small study set out to explore whether social workers here fared any better.

\section{Method}

A qualitative narrative design using semistructured interviews was chosen to provide the opportunity to allow social workers to tell their stories. Hinchman and Hinchman (1997) propose that "narratives (stories) in the human sciences should be defined provisionally as discourses with a clear sequential order that connect events in a meaningful way for a definite audience and thus offer insights about the world and/or people's experiences of it" (p. 16). A qualitative research approach was thus chosen to enable participants to tell their story and have their voices heard which, as noted by Frank (1995), "values the teller" (p. 18). The research questions were:

- What has been the experience of those social workers who have spoken out about poor or unethical practice?

- From where did they receive the support needed to stand firm and be guided by their code of ethics?

- What is the role of the social work professional association in situations where whistleblowing has occurred?

- Who should provide support to social workers who engage in whistleblowing?

The aim of the project was to inform social workers and professional bodies in Aotearoa New Zealand by creating an awareness of potential consequences that may arise when, adhering to the ANZASW Code of Ethics, a decision is made by a practitioner to address the concerns arising from witnessing unsafe practice.

The participants in the study were social workers who were members of ANZASW. This was a pragmatic choice as it was possible to contact over 3000 social workers via email through the organisation's database. Inclusion criteria were that the participants had to be current members of the ANZASW with direct experience of observing practice they perceived to be 
unsafe or unethical. They had thus faced the dilemma of whether or not to speak out and blow the whistle.

\section{Recruitment}

A total of 82 initial responses to this advertisement were received, with 23 respondents further returning completed consent forms. Some of the original respondents did not make contact again, while some did, stating reasons for not wanting to proceed. The main reason was time constraint, but also, some potential participants expressed fear of being recognised and suffering further repercussions. A final sample of 10 participants who met the search criteria and were available during the data-collection period were interviewed in the study, in person or by phone.

The interviews were between 60 and 90 minutes long, were digitally recorded and transcribed verbatim. The first author listened to the recordings and read the transcripts many times as recommended by Guest, MacQueen, and Namey (2011) who suggest: "... for an exploratory study, the researcher carefully reads and rereads the data, looking for key words, trends, themes, or ideas in the data that will help outline the analysis before any analysis takes place" (pp. 7-8). This approach is also supported by Ryan and Bernard (2003, p. 89) who write: "repetition is one of the easiest ways to identify themes". Recurring ideas and concepts were coded as patterns were identified and a set of five themes developed.

\section{Ethical considerations}

This project received approval from the University of Auckland Human Participants Ethics Committee. There were several ethical issues that needed to be considered prior to commencing the study. The research team was concerned about the possible information regarding reportedly unethical or harmful conduct that may have emerged from the interviews, and how this information would be dealt with. It was decided that such situations would be discussed in supervision and further advice from ethics advisors would be sought if necessary. As participants had potentially experienced distress through their whistleblowing activities, the mental and spiritual health of participants and the primary researcher were also important to consider. Information about support was provided to the participants and the primary researcher received regular clinical and research supervision during the research process.

All names have been changed to protect the confidentiality of participants. It is important to note that information about the incidents that triggered whistleblowing responses was not investigated for validity. Firstly, this is not practicable. Secondly, the authors feel uncomfortable about such hypothetical interrogation of the actions of a third or even fourth party who is present in the narratives. These other parties could not consent and we present sparse details of the incidents that led to whistleblowing, only as part of the narrative provided. In reporting the experiences of our participants, we neither support nor refute the veracity of the concerns that poor or harmful practice occurred. Saunders, Kitzinger, and Kitzinger (2015, p. 617) note that research conduct of "confidentiality also includes keeping private what is said by the participants, something only achievable through researchers choosing not to share parts of the data." In this case, some details are left out or obscured in order to protect participants and others. Saunders et al. (2015, p. 620) cite Tolich (2004, p. 101) who refers to confidentiality as "external" where confidentiality relates to the "protection against identification" of those participating and connected others. They note that participants might be identified by some members of the intended audience for the research, as applies in this study, where we aim to inform practitioners. These aspects have been carefully considered in the writing up of the findings. 


\section{Findings}

Analysis of the data produced many categories for analysis and a final set of five themes was identified. Five major themes were developed from the analysis: Identifying unsafe practice; Addressing the concerns; Where do you go for support?; Personal impact: social work ... A career or "just employment"? and Learning from experience. Brief examples from the interview data are used to illustrate themes and all participants are referred to by pseudonyms.

\section{Identifying unsafe practice}

Social workers interviewed identified a variety of unsafe or negative issues in the workplace ranging in seriousness. Each issue was different and the concerns discussed fell into two separate categories: firstly, those involving unsafe social work practice by colleagues; and secondly, concerns with organisational practice and/ or policies that were believed to contribute to unsafe practice. Some of the participants were experienced social workers with the confidence to address their concerns directly. However, those who were either new to social work or to their place of employment were either unsure of policies and procedures, or unwilling to take matters further at that particular time.

Many incidents related to matters of professional roles and boundaries, where participants felt that colleagues were not practising safely. One of the tensions felt by potential whistleblowers reflected the need to manage ongoing professional relationships with peers along with addressing concerns with management.

One participant, Amanda, had worked in statutory organisations throughout her social work career and spoke of two separate occasions when she became concerned about a colleague's practice. The first incident occurred when she became aware of a relationship between a colleague and a close family member of the colleague's client.
A second incident involved a colleague requesting a service-user's bank details. Although the participant believed there was no intent to defraud, this colleague left themselves vulnerable to potential allegations: "I knew that they had some honest reasons for what [they were] doing, but the practice was not safe."

Another participant, Bev, found that her name had been used in a legal document written by a social work colleague. Bev had never worked with the family concerned:

... my name was mentioned several times through the affidavit saying that I had involvement that I had not had and that I had completed assessments that I had not completed ...

Carlos first worked as a residential care worker when he observed a senior colleague physically assaulting a non-verbal resident who had an intellectual disability and therefore could not tell anyone what had happened: “... because I was so young, it took me ages to actually say to the manager what the bruising was on this person's face ... it took me probably two or three weeks."

These issues and concerns reflected different expectations and standards among practitioners and caused conflict in the professional context. Social workers also identified organisational practices and processes that were antithetical to the values and ethics of good social work.

Dorothy was an experienced statutory social worker who encountered what she categorised as unethical organisational work practices. She believed that, in her organisation, when her colleagues were not practising safely it was usually due to pressure they were under due to having unmanageable caseloads. Dorothy was increasingly concerned about time frames between referral and action. The issue of unmanageable caseloads was also mentioned by Frances who had experienced a number of issues in the workplace and had always 
spoken out about these situations. Frances said she had increasingly seen changes and a deterioration in the way workplace issues were managed. "We should be a lot more active. We do it with our clientele and why can't we [advocate for] our staff?"

Issues with management and organisations were not exclusive to statutory organisations. Verity worked for a community organisation. On one occasion, Verity faced a challenging issue and went to her manager hoping to obtain some guidance and support. Her manager responded by becoming angry and walking away. Verity followed the manager into their office to get some clarity about what was happening and "[they] physically pushed me, shoved me out and shut the door."

These social workers clearly hoped that that organisations and management had responsibility and a role to play in ensuring that social workers practised safely and ethically in their places of employment. Addressing their concerns, however, was not always made easy.

\section{Addressing the concerns}

All of the social workers felt that it was important to address the concerns that they had witnessed or been a part of, and felt, at the time, that they were doing the "right thing" that was consistent with their ethics and values. Some participants felt comfortable speaking directly to the colleague concerned but others felt this depended on the seriousness of the situation, and whether the concerns needed to be escalated directly to management.

Amanda's initial response upon observing concerning practice was to speak directly with the colleague concerned; "I personally don't agree with doing things anonymously, unless there was something I felt very unsafe with." However, she went on to say that, "[t] here might also be times when it is actually so dangerous and, at the point that they have put someone at risk, then it has to go to the next level."
In the first situation recounted by Amanda, she reported that her colleague was grateful for the intervention due to their discomfort with the relationship but had been feeling unable to sort things out. They jointly took the matter to their supervisor and the issue was resolved to the satisfaction of all parties. However, the second incident that Amanda observed, concerning the client's bank details, was less straightforward and when she addressed the potentially serious practice issue, the colleague concerned completely minimised the matter. This increased Amanda's concern and she made the decision to take the issue to a senior colleague and kept following up to ensure the concern was addressed. Amanda compared her two different experiences and commented on the fact that the chain of command differed greatly between the two organisations. The first issue was easier to address directly given that the organisation had social workers in all positions of management, who had clear understanding about practice-related issues. The line manager, was not well informed about social work ethics and therefore, in Amanda's opinion, was quick to put any complaints down to personal issues: "if they don't understand that they are practice issues, then the response is 'well maybe it's just a personal issue'."

Bev reported disappointment with the response of her manager regarding her name being placed on court documents. This person had appeared quite blasé about what had occurred. Bev then took the matter to her supervisor who also did not appear too concerned about what had occurred. "I met with those two people several times, saying 'I'm not happy about this, this is not okay' and they ended up saying 'well you can lay a complaint if you like.'" Bev was anxious about jeopardising workplace relationships by laying a complaint. Making a formal complaint is not a straightforward process. Indeed, the stories that unfolded during the research interviews demonstrated that there are often many things to take into consideration, and that such processes are very complex. 
Helpful management responses did occur. Amanda believed the positive outcome achieved from the first incident, where she was able to address her concerns directly with her colleague, was due not only to the fact that her colleague was receptive but also that the supervisor/line manager was a trained social worker who understood safe practice and ethical dilemmas. She believed this ensured the matter was dealt with appropriately. For those who could not have their concerns addressed appropriately by management, the decision was made to escalate them by initiating a formal process via organisational complaints procedures.

\section{Where do you go for support?}

Most of the participants recognised the need to receive support throughout the process and sought this through various channels. Supervision was the first place that many of the participants sought support from, with differing results. It was clear that those who received only internal supervision did not feel this was always a safe place to raise their concerns, as noted by Dorothy:

"Because supervision that we get in here, a lot of it is around management stuff." Of the 10 participants, only two received external supervision and they all recognised how helpful this was during their whistleblowing experiences.

Amanda received support from a professional supervisor who was external to the organisation. She noted how important this was to her and she was determined to continue receiving external supervision from the outside organisation stating "I get support from her and I am very honest with her about anything that happens here." Of all the participants interviewed, Irene expressed the most satisfaction with the supervision support she received, as this assisted her when she needed to make clear ethical decisions. She stated: "Well I have an external supervisor, yes, and I have internal group supervision."
Neither Verity, Bev nor Dorothy had access to external supervision and all commented that this made the issues they faced more difficult. Dorothy said that she would love external supervision as "it enables you to step past the institutional barriers, that you sometimes don't see, the pressures and you stand outside it." Bev had access only to internal supervision and stated she did not have any supervision support when dealing with her issue and changed supervisors after this experience. While external supervision was identified as preferable to internal, Jan was grateful for the supervision she received from her internal supervisors as she recognised their deep experience-they helped her "through my own personal journey of understanding what a practitioner was."

Many participants in this study often found themselves isolated from peer support. This isolation led to participants feeling vulnerable, unable to move forward and, as Carlos stated, "there is no support and it actually becomes a very lonely and isolated place." When he first became a whistleblower, co-workers acted as though Carlos had "dobbed a colleague in." Carlos reported "basically I was ostracised ... it was really hard." Irene also experienced a degree of ostracism: "I know some who no longer speak to me, and one in particular if we're in the same room, I know they blame me, when I know I was right with what I did."

Bev believed the reason her colleagues were reluctant to support her was that "everyone just wanted [the issue] to go away, it was a done deal." Verity also had hoped for more collegial support, as she knew others recognised their manager's inability to supervise. Being known as a strong advocate, Verity felt she had "been made a scapegoat, because everybody wanted me to make this complaint, for their own reasons." After she made the complaint, Verity found her colleagues quickly changed their minds and chose to maintain their alliance with management. 
Professional bodies can offer support, although no participant in this study approached the Social Workers Registration Board (SWRB) and those who approached ANZASW had varied experiences. The assault on Verity occurred immediately prior to a holiday period when there were limited services available but she did contact the ANZASW who were very helpful, as was the Employment Assistance Programme (EAP). Verity approached EAP and saw a "fabulous man who was a social work consultant ... many years' experience and he encouraged me to make a complaint. It wasn't his decision, but he encouraged me to make one."

Many of the social workers found their unions were not always in a position to offer the support that was needed, because of conflicts of interest. For example, Carlos was a member of the union, however, the person he witnessed assaulting the client was also a member and had already approached and was receiving support from the union. He was unaware that he could have requested an independent person to work with him.

\section{Personal impact: social work ... a career or "just employment"?}

Participants reported that they were aware of many different kinds of retaliation that could be experienced. One perceived, yet often unproveable, method was for management to ensure the whistleblowers did not progress in their careers. All participants reported experiencing some form of reprisal and, while some were very clear they had done the right thing and stated they would do the same again, others believed the cost was too great and they would now remain quiet if they were in the same situation again. "Would I ever do it again? Hell no!" (Amanda). Frances was very clear that her inability to progress or be promoted was a direct result of her speaking out. Dorothy also believed that the fact she had often escalated concerns was one of the main reasons she has not progressed within her organisation “... well I guess I never got those jobs as supervisor ... I might have made a good supervisor."

Frances believed she may have had opportunities to gain other employment outside of her organisation but had to consider the needs of her family and this meant keeping stable, secure employment. "Yes, it's about having that security base so that you can get your kids through, which is what I have done." Verity was concerned about receiving a fair reference from the manager, if she did manage to find other employment, and she realised it would not be ethical for her to sit in an interview and speak of management negatively to try to deflect from a possible bad reference. “... now I am stuck in a bloody job ... My only hope is that she would desperately want to get rid of me and give me a reference. But I don't believe she is fair enough to."

\section{Symptoms of stress}

Most participants mentioned the stressrelated symptoms they linked to the consequences of speaking out. These symptoms could be ongoing long after the whistleblowing and its outcomes occurred. Some participants reported physical symptoms that they related to the stress they were under, while others were affected emotionally. When Frances spoke of her colleague, who she supported in the employment court, she related "... the strain got to her and she ended up on the sickness benefit." Verity became anxious about how she would return to the workplace. She stated: "I was feeling physically sick." Irene made reference to the impact this had had “... you have to be fairly strong and fairly clear about what your intentions are and every time I've felt sick to my stomach."

For many of the participants, their emotional state was greatly affected by speaking out. Whilst they were clear about their need to expose issues, they were ill prepared for the emotional impact from the consequences of 
their speaking out: "my journey was sad ... that it led to just an utter break down of who I was" (Jan). Some of the incidents related by participants had occurred five or more years ago and they reported how their experiences still impacted on them. For some, the impacts are felt personally and, for others, the impacts directly affect how they see their future prospects in social work.

... I've carried it with me all these years because, you know I just cannot believe how stressful that is and I believe it's made me very sceptical, I guess, about professional practice. (Bev)

\section{Learning from the experience}

It was apparent that the participants in this study came forward to tell their stories because their experiences had been profoundly affecting and led to new understandings, many negative. Carlos recounted that he later became a manager and he was instrumental in initiating what they called a whistleblowers' policy. This policy was a way of putting things in place to make it safer for social workers to report incidents. A group of managers put the policy together and provided a support team of staff from other organisations. He stated that they used peers to support people.

Some participants were asked if they would, on reflection, do things differently. Verity was very clear, she said, "absolutely, I would never have gone through a formal process, because now I'm stuck in [the] bloody job." Jan felt on reflection that she took the easy way out when she resigned after whistleblowing. If she could do it all over again, she would remain in the position and continue to push for change.

At the end of the interviews, participants were asked what advice they would now give to a colleague who was going through a similar issue to what they had experienced. Jan commented that if a colleague came to her with a similar concern, she would say "you know, let's reflect on this, discover and explore; get them to think about how this might affect them, if they were to go the extra mile and speak out." For Bev it was very clear, she stated "I think the main thing I would say is, 'whatever you do, don't let it go. I don't know where you would go but let's find a way'." Both emphasised that support would be offered.

\section{Discussion and recommendations}

While there was initially a strong response to the email invitation, due to the project timeframe, only 10 social workers were eventually able to be interviewed. As such, care must be taken not to generalise from the experiences of the small group of participants. The findings do, however, support the need for some action to be taken in future to improve the outcomes for people who report unsafe practice.

Although there were many different issues faced by the participants in this study, common themes support the general consensus in the literature that, although reporting unsafe practice should be encouraged to ensure safety of clients, the reality is often very different and stressful for the whistleblower. Deciding to speak out has had profound consequences for many of those interviewed for this study including retaliation, isolation, stress, emotional and physical impacts and, in some cases, implications for whistleblowers' careers and even workplace safety. As Ash (2016) notes in her recent book, whistleblowers cannot expect to be "hailed a hero" (p. 166). It is essential that social workers seek to develop solid support networks when they first decide to speak out. This has been highlighted from the participants in this study who all recognised the importance of having support, particularly when there is a higher likelihood of repercussions. External supervision, while not available to all because of costs and employer policy, might be extremely valuable because of the confidentiality, independence and sense of safety it offers (Beddoe, 2011). 
This research raises many issues for the social work profession. Tensions are identified for social workers whose loyalties are divided between clients, colleagues, regulatory bodies and the organisation that employs them. It is important to situate these tensions within the wider, risk-averse climate in which intensified regulation leads to complex inter-agency dynamics, with increasing power situated in state regulatory mechanisms. Fairness, safety, transparency and principles of natural justice must prevail when whistleblowers act, but these apply equally to the practitioners accused of misconduct. As the recent study by Worsley, Leigh, and McLaughlin (2017) has noted, the consequences of complaints can be devastating for the accused as well. There is a lack of a clear pathway, beginning when concerns are first identified, and including inadequate reporting systems which deter practitioners from speaking out, or where action is delayed, causing harmful situations to escalate. The authors support the recommendations of Green and Latting (2004) and others that employers need to acknowledge whistleblowing as advocacy in the first instance, and should offer all parties a clear process to address and contain these situations within their organisations.

It is clear that most of the social workers in this study recognised both managerial and organisational failures to address concerns. This theme is also evident in the literature and professional bodies in other countries have tried to address this by including expectations of organisations/ agencies into codes of conduct and/or codes of ethics. As professionals, social workers must make their practice more transparent, by not accepting unethical, unprofessional practice in the workplace and by being prepared to speak up about these issues. When they blow the whistle, they should be recognised as ethical practitioners who care about their profession, and should receive support from colleagues, professional bodies and their employing agencies.
Within our context, the two main professional bodies are the ANZASW and the SWRB, the Crown entity charged with the responsibility of administering a nonmandatory system of registration for New Zealand social workers. As noted earlier, the ANZASW Code of Ethics (2008) encourages members to report if the concern cannot be resolved by other means. The SWRB Code of Conduct states:

... if confronted by a colleague's professional negligence, unethical behaviour or misconduct or behaviour that impacts negatively on their social work practice or their profession, the social worker should address the matter through established organisational or legal channels. (SWRB, 2005, p. 8)

However, neither the professional association nor the regulator are clear about what constitutes an appropriate body or an established organisational or legal channel. It is hoped that this study might lead to the development of greater guidance. We also strongly recommend that professional bodies extend clear advice on the potential of the Protected Disclosures Act to offer protection and guidance to whistleblowers (Office of the Ombudsman, n.d.). A very simple first step would be links to guidance on body websites. The authors have also incorporated teaching on whistleblowing into the social work education curriculum, and would recommend other schools of social work follow suit by supporting students to consider ethical scenarios (see Martin, 2016 for example).

The last words go to Bev who asked where the accountability is in social work. She did not want revenge or anything to happen to the social worker, but she did want acknowledgement of the wrong and believed the social worker should have been held accountable for her actions: "Don't call yourself a social worker if you are not going to practise along the principles [of] the Code of Ethics." 


\section{References}

Ash, A. (2016). Whistle blowing and ethics in health and social care. London, UK: Jessica Kingsley.

Aotearoa New Zealand Association of Social Workers. (2008). Code of Ethics (2nd Rev.), Christchurch, New Zealand: Author.

Banks, S. (2008). Critical commentary: Social work ethics. British Journal of Social Work, 38(6), 1238-1249. doi:10.1093/bjsw/bcn099

Beddoe, L. (2011). External supervision in social work: Power, space, risk, and the search for safety. Australian Social Work, 65(2), 197-213. doi:10.1080/031240 7x.2011.591187

Beddoe, L., Davys, A. M., \& Adamson, C. (2014). Never trust anybody who says "I don't need supervision": Practitioners' beliefs about social worker resilience. Practice, 26(2), 113-130. doi:10.1080/09503153.2014.896888

De Maria, W. (1996). The welfare whistleblower: In praise of troublesome people. Australian Social Work, 49(3), 15-24.

De Maria, W., \& Jan, C. (1994). Wounded workers Queensland whistleblower study. Brisbane, QLD.: University of Queensland, Department of Social Work and Social Policy.

Doel, M., Allmark, P., Conway, P., Cowburn, M., Flynn, M., Nelson, P., \& Tod, A. (2010). Professional boundaries: Crossing a line or entering the shadows? British Journal of Social Work. 40(6), 1866-1889. doi:10.1093/bjsw/ bcp106

Frank, A. (1995). The wounded storyteller: Body, illness and ethics. Chicago, IL: University of Chicago Press.

Glazer, M. P., \& Glazer P. M. (1989). The whistleblowers: Exposing corruption in government and industry. New York, NY: Basic Books.

Greene, A., \& Latting, J. (2004). Whistle-blowing as a form of advocacy: Guidelines for the practitioner and organisation. Social Work, 49(2), 219-230.

Guest, G., MacQueen, K. M., \& Namey, E. E. (2011). Applied thematic analysis. London, UK: Sage.

Hedin, U-C., \& Månsson, S-A. (2012). Whistleblowing processes in Swedish public organisations-Complaints and consequences. European Journal of Social Work, 15(2), 151-167.

Hinchman, L. P., \& Hinchman, S. K. (Eds.). (1997). Memory, identity, community: The idea of narrative in the human sciences. Albany, NY: State University of NY Press.

Hunt, G. (Ed.). (1998). Whistleblowing in the social services: Public accountability and professional practice. London, UK: Arnold.

Jackson D., Peters K., Andrews S., Edenborough, M., Halcomb E., Luck L., ... Wilkes L. (2010). Understanding whistleblowing: Qualitative insights from nurse whistleblowers. Journal of Advanced Nursing, 66(10), 2194-2201.

Kline, R., \& Preston-Shoot, M. (2012). Professional accountability in social care and health: Challenging unacceptable practice and its management. London, UK: Sage.

Lennane, K. J. (1993). "Whistleblowing": A health issue. British Medical Journal, 307(6905), 667-670. doi:10.1136/bmj.307.6905.667
Lennane, J. (2012). What happens to whistleblowers, and why. Classics in Social Medicine, 6, 249-257

Mansbach, A., \& Bachner, Y. (2009) Self-reported likelihood of whistle blowing by social work students. Social Work Education, 28(1), 18-28.

Martin, S. (2016). Being Pono: Ethical dilemmas as learning tools for student social workers. Aotearoa New Zealand Social Work, 28(1), 68-70. doi:10.11157/anzswjvol28iss1id121

McAuliffe, D., \& Sudbery, J. (2005). Who do I tell?: Support and consultation in cases of ethical conflict. Journal of Social Work, 5(1), 21-43. doi:10.1177/1468017305051362

McDonald, S., \& Ahern, K. (2002). Physical and emotional effects of whistleblowing. Journal of Psychosocial Nursing and Mental Health Services, 40(1), 14-27.

Moore, M., \& McAuliffe, E. (2010). Is inadequate response to whistleblowing perpetuating a culture of silence in hospitals? Clinical Governance, 15(3), 166-178.

Office of the Ombudsman. (n.d.). Protected disclosures/ whistle-blowing. Retrieved from http://www.ombudsman. parliament.nz/what-we-do/protecting-your-rights/ protected-disclosures-whistle-blowing

Preston-Shoot, M. (2010). On administrative evil-doing within social work policy and services: Law, ethics and practice. European Journal of Social Work, 14(2), 177-194.

Protected Disclosures Act. (2000). Wellington, NZ: New Zealand Government. Retrieved from http://www.legislation.govt.nz/act/public/2000/0007/ latest/DLM53466.html

Ryan, G. W., \& Bernard, H. R. (2003). Techniques to identify themes. Field Methods, 15(1), 85-109. doi:10.1177/1525822x02239569

Saunders, B., Kitzinger, J., \& Kitzinger, C. (2015). Anonymising interview data: Challenges and compromise in practice. Qualitative Research, 15(5), 616-632. doi:10.1177/1468794114550439

Social Workers Registration Board. (2016). Code of conduct for social workers, 1. 3-10. Wellington, NZ: Author.

Tolich, M. (2004). Internal confidentiality: When confidentiality assurances fail relational informants. Qualitative Sociology, 27(1), 101-106.

Whistleblowers Australia Inc. Retrieved from http://www.whistleblowers.org.au/

Worsley, A., Leigh, J., \& McLaughlin, K. (2017). A subject of concern: The experiences of social workers referred to the Health and Care Professions Council. British Journal of Social Work. doi:10.1093/bjsw/bcx005 